\title{
Water for bioenergy: A global analysis
}

Chapter in Climatic Change · January 2012

DOI: $10.1017 / \mathrm{CBO} 9780511920899.007$

CITATIONS

2

3 authors:

Winnie Gerbens-Leenes

University of Groningen

53 PUBLICATIONS 2,367 CITATIONS

SEE PROFILE

Th.H. Van Der Meer

University of Twente

119 PUBLICATIONS 1,985 CITATIONS

SEE PROFILE

Some of the authors of this publication are also working on these related projects:

Seasonal and long-term prediction of low flows in the Rhine basin View project

Socio-hydrology and drought in the Jaguaribe basin: Spatiotemporal interdependencies between water use and water availability View project
READS

52

Arjen Hoekstra

University of Twente

355 PUBLICATIONS 18,991 CITATIONS

SEE PROFILE 


\title{
4 \\ Water for bioenergy: A global analysis \\ P. WINNIE GERBENS-LEENES, ARJEN Y. HOEKSTRA, AND \\ THEO H. VAN DER MEER \\ University of Twente, Twente, Netherlands
}

\begin{abstract}
Agriculture is by far the largest water user. This chapter reviews studies on the water footprints (WFs) of bioenergy (in the form of bioethanol, biodiesel, and heat and electricity produced from biomass) and compares their results with the WFs of fossil energy and other types of renewables (wind power, solar thermal energy, and hydropower). WFs for bioenergy vary, depending on crop type applied, production location, and agricultural practice. The most water-efficient way to generate bioenergy is to use biomass for heat generation, with electricity generation being the second best option. Biofuel production requires roughly twice as much water as bioelectricity. Regarding biofuels, bioethanol has smaller WFs than biodiesel. For example, the WF of rapeseed biodiesel is four times larger than the WF of sugarcane ethanol and seven times larger than the WF of sugar beet ethanol. Global weighted ethanol WFs increase in the order of sugar beet, potato, sugarcane, maize, cassava, barley, rye, paddy rice, wheat, and sorghum and range between 60 and $400 \mathrm{~m}^{3} /$ GJ. For sugar beet, maize, and sugarcane, differences between regions are large. The European Union, northern Africa, and the United States have relatively small WFs for ethanol from sugar beet and maize, while eastern Europe has large WFs. Global weighted average biodiesel WFs increase in the following order: palm oil $\left(95 \mathrm{~m}^{3} / \mathrm{GJ}\right)$, soybean and rapeseed $\left(400 \mathrm{~m}^{3} / \mathrm{GJ}\right)$, and jatropha $\left(570 \mathrm{~m}^{3} / \mathrm{GJ}\right)$. Conversely, the WFs of fossil fuels are relatively small. Finally, the WF of hydropower varies widely between 0.5 and 850 $\mathrm{m}^{3} /$ GJ. Our results provide new insight into the impacts of bioenergy on the use and pollution of freshwater. This knowledge is a valuable contribution to future research and for policies concerning energy needs, freshwater availability, and the choice whether to allocate water to food or energy production.
\end{abstract}

Keywords: renewable, water footprint 


\section{Introduction}

Freshwater is essential for the functioning of society. Water use in agriculture, industry, and households has increased sharply in the twentieth century (Shiklomanov, 1997). Human activity consumes and pollutes great amounts of water, particularly through agricultural production (Hoekstra and Chapagain, 2007). Freshwater is a scarce natural resource. Most water on Earth is saline and cannot be used for societal needs. The oceans contain about 97.5 percent of available water in the form of saltwater. Of the remaining 2.5 percent of freshwater, most is not accessible because it forms part of ice or snow covers (Shiklomanov, 1997). Although the amount of water on the planet is constant, the annual freshwater supply in the form of precipitation is limited.

Natural precipitation is the main provider of agricultural water. This is the so-called green water (Hoekstra et al., 2011). When precipitation is insufficient, farmers can apply irrigation, or blue water. ${ }^{1}$ Today, about 80 percent of the agricultural water requirements are met by precipitation, with the rest withdrawn from other sources such as rivers and lakes (de Fraiture and Berndes, 2009). These withdrawals account for 70 percent of all human water use (UNEP, 2009).

Freshwater is becoming, more and more, a global resource because water-intensive products are traded on global markets. International trade results in a spatial disconnection between consumers and the water resources used for making consumer products. Water footprint (WF) research shows the relationship between consumer goods and water consumption along supply chains, thereby addressing the link between consumption and production. By doing this, WF research offers a new perspective on how a consumer or producer relates to the use of freshwater systems (Hoekstra et al., 2011). The WF concept provides a tool to calculate water needs for consumer products and provides an indication of the total amount of freshwater used, directly and indirectly, along product supply chains (Hoekstra et al., 2011). The WF of a product, for example, bioethanol, is the volume of freshwater used to produce the ethanol, measured over the complete supply chain. Important water-intensive products are crop and livestock commodities, natural fibers, and bioenergy.

The next decades will see an increased demand for food (Tilman et al., 2002; Bruinsma, 2003) as well as an increased demand for biofuels (Stromberg et al., 2010). The corresponding necessary growth of agricultural output can be achieved in three ways: (1) an increase of agricultural land areas, (2) an increase of yield levels per unit of land (increase of land productivity), or (3) an increase of cropping intensities (e.g., by increasing multiple cropping and shortening fallow periods) (see also Chapter 2). If agricultural land areas are increased, water use will probably increase by the same

${ }^{1}$ The irrigation sector has increased enormously in past decades and is currently the largest water user, accounting for $61 \%$ of total water withdrawal globally. Between 1900 and 1995, the irrigated area expanded fivefold, from 50 million to 250 million ha. Half of these irrigated areas are located in just four countries: China, India, the United States, and Pakistan (Shiklomanov, 1997). 
factor, given that water input per unit of land usually remains the same. The increase of yield levels or cropping intensities might also increase water use in those cases in which water is the limiting factor for crop growth.

Bioenergy production may divert land, water, and other resources away from the production of food and feed (Fischer et al., 2009). In many countries, agricultural water use competes with other uses such as urban supply and industrial activities (Falkenmark, 1989), causing the aquatic environment to show signs of degradation and decline (Postel et al., 1996). Crop growth (for biomass production) requires freshwater, and agricultural activity associated with feedstock production is by far the largest user of water, followed by industrial activities (WWAP, 2009). In general, increased biofuel production will probably require more water (Berndes, 2002; de Fraiture et al., 2008), and a shift from fossil energy toward bioenergy might put additional pressure on freshwater resources.

Today, some of the world's most important agricultural areas show signs of water scarcity $^{2}$ (de Fraiture and Berndes, 2009) such as northern India, Pakistan, and northern China (Shah et al., 2007). China and India will account for one-third of the world population and will demand one-third of the world's energy supply by 2030 (de Fraiture and Berndes, 2009), so they aim to partly replace transport fuels from fossil sources by biofuels such as bioethanol and biodiesel (Yang et al., 2009; MNRE, 2008) (see Chapters 1 and 10). This is expected to increase water scarcity because China and India have already overexploited their natural water resources (de Fraiture et al., 2008; Muller et al., 2008). Sufficient water for agriculture is available in Latin America and sub-Saharan Africa (Muller et al., 2008), excluding South Africa (Jewitt et al., 2009). All the preceding suggests that biofuel-related water consumption might aggravate water scarcity in many countries. In all, about 30 developing countries face water scarcity, and it is expected that by 2050 , over 50 developing countries will suffer from water shortages (Fischer et al., 2009). It is therefore important to have insight into the relationship between agricultural output, water consumption, and water availability to properly allocate the water to food or biofuels.

Biofuel production does not only affect the quantity of water resources but can also affect the quality of such resources (Stromberg et al., 2010). Apart from water, other important agricultural inputs for feedstock production include nutrients (such as nitrogen and phosphorus) and agrochemicals for controlling pests, diseases, and weeds. When agricultural yields increase, the demand for nutrients expressed per unit area also increases (de Wit, 1992). Part of these inputs leach to water bodies and cause water pollution (UNEP, 2009; Simpson et al., 2009; Stromberg et al., 2010). Ethanol production, for example, has serious implications for coastal water quality and will almost certainly worsen already serious hypoxic conditions in many locations around

\footnotetext{
${ }^{2}$ Water shortages are the result of a mismatch between demand for freshwater and its availability over space and time.
} 
the world (Simpson et al., 2009). Sugarcane expansion is one of the main drivers of increased fertilizer and agrochemical use in Brazil, which has been linked to water pollution and ecosystem deterioration (Martinelli and Filoso, 2008) (see Chapter 6).

In this chapter, we employ the WF concept to assess the water requirements of different biofuel production practices and compare them with the WFs of fossil energy carriers (natural gas, coal, and crude oil). Initially, we summarize the WF methodology (Section 2), and we review the main bioenergy WF studies that have estimated WFs per unit of bioenergy $\left(\mathrm{m}^{3} / \mathrm{GJ}\right)$ (Section 3 ). We cover biofuels (bioethanol and biodiesel) as well as heat and electricity generated from biomass. Subsequently, we compare the results generated using the WF methodology with the results of studies that have used other methodologies. Next, we compare WFs of bioenergy with WFs of fossil energy carriers, nuclear energy, and the WFs of renewables (wind power, solar thermal power, and hydropower). The chapter gives WFs of various types of bioenergy in meters cubed per unit of energy $\left(\mathrm{m}^{3} / \mathrm{GJ}\right)$ and covers the main producing countries, including developing countries, transition countries, and industrialized countries.

\section{Methodology}

The WF is a multidimensional indicator, giving water consumption volumes by source and polluted volumes by type of pollution. The WF of a product is defined as the volume of freshwater used for its production at the place where it was actually produced (Hoekstra et al., 2011). In general, a product's actual water contents are negligible compared with its WF. For many products, such as bioenergy, the water used (or consumed) during the agricultural production stage makes up the bulk of the product's total life cycle water use.

The WF concept includes three components - green, blue, and gray water - and distinguishes between direct and indirect water use, taking into account the water use along supply chains. The components of WFs are specified geographically and temporally. The green WF refers to consumption of green water resources, that is, rainwater stored in the soil as soil moisture and water that stays on top of the soil and on the vegetation. The blue WF refers to consumption of blue water resources, that is, fresh surface water and groundwater. The gray WF refers to pollution and is defined as the volume of freshwater required to assimilate the load of pollutants based on existing ambient water quality standards (Hoekstra et al., 2011). The gray component of the WF is shown in equation (4.1):

$$
\text { GrayWF }=\frac{\alpha * \mathrm{AR}}{\frac{C_{\max }-C_{\mathrm{nat}}}{Y}},
$$

where $\mathrm{AR}$ is the chemical application rate to the field per hectare $(\mathrm{kg} / \mathrm{ha}), \alpha$ is the leaching-runoff fraction, $C_{\max }$ is divided by the maximum acceptable concentration 


\section{Box 4.1. Sample WF analysis for sugarcane ethanol in Brazil and India}

Brazil is the largest sugarcane producer, with 29 percent of global sugarcane production, followed by India, which produces 21 percent (FAO, 2008a). Often the sugarcane crop is harvested manually. At the plant, the stalks are chopped into pieces and washed to remove trash. Next the cane is crushed, producing a juice, the ingredient for ethanol and sugar, and a residue, the bagasse (Cheesman, 2004).

Process water use is small compared to agricultural water use. Traditional water use in a sugarcane mill is about $21 \mathrm{~m}^{3} /$ ton of processed cane (Macedo, 2005). New techniques have decreased water use to $0.92 \mathrm{~m}^{3} /$ ton of cane. The São Paulo State Plan on water resources estimated the water use in 1990 at $1.8 \mathrm{~m}^{3} /$ ton of cane (Macedo, 2005). For Brazil and India, we have calculated a total WF, green, blue, and gray, of 209 and $256 \mathrm{~m}^{3} /$ ton. This means that in Brazil, the process water is about 1 percent of the total water use in the whole supply chain. For India, we also estimate that process water use is almost negligible when compared to water use over the entire supply chain.

of the pollutant $\left(\mathrm{kg} / \mathrm{m}^{3}\right), C_{\text {nat }}$ is the natural concentration for the pollutant considered $\left(\mathrm{kg} / \mathrm{m}^{3}\right)$, and $Y$ is the crop yield (ton $/ \mathrm{ha}$ ).

The pollutants generally consist of fertilizers (nitrogen, phosphorus, etc.) and agrochemicals. One has to consider only the waste flow to freshwater bodies, which is generally a fraction of the total agricultural application to the field. One needs to account for only the most critical pollutant, that is, the pollutant for which the preceding calculation yields the highest water volume (Hoekstra et al., 2011).

The WF of biofuels is dominated by the agricultural phase, that is, feedstock production. Other processes during the biofuel's life cycle, such as feedstock transportation and processing, are much less water intensive. Box 4.1 provides a simplified WF analysis for sugarcane ethanol in Brazil and India.

It should be noted that all WF studies presented in this chapter have been based on the assumption that crop water use is equal to crop water requirements. However, when actual water availability is lower and water stress occurs, the WF analysis overestimates crop water use. This assumption differs from the method applied by Chiu et al. (2009), who estimated the water requirements of U.S. ethanol based on measured irrigation and arrived at lower values. In their study, Mekonnen and Hoekstra (2010) find lower WFs because they also account for water shortages, thus estimating the actual water consumption. With respect to agricultural yields, the studies presented and reviewed in this chapter have taken into account actual yields, which, in many cases, can be increased in the future without increasing water use per unit of product. This means that future WFs per unit of energy can actually be significantly smaller than the ones currently calculated. Conversely, regarding the efficiency of obtaining electricity or biofuels from biomass, the studies have made optimistic assumptions 
by taking theoretical maximum values, or values that refer to the best available technology. This means that the resulting WFs are conservative.

\section{Overview of bioenergy WF studies}

\subsection{Bioethanol}

Gerbens-Leenes and Hoekstra (2012) performed a detailed study of bioethanol WF (green, blue, and gray) for the main producing countries as well as the main producing U.S. states. Countries and feedstocks included in this analysis are as follows:

- Sugarcane. Argentina, Australia, Belize, Brazil, China, Colombia, Cuba, Egypt, Ethiopia, Guatemala, India, Indonesia, Morocco, Pakistan, Peru, the Philippines, South Africa, Thailand, the United States, Venezuela, and Vietnam

- Sugar beet. Belgium, China, the Czech Republic, Denmark, Egypt, France, Germany, Iran, Italy, Japan, Morocco, the Netherlands, Poland, the Russian Federation, Serbia, Spain, Turkey, Ukraine, the United Kingdom, and the United States

- Maize. Argentina, Brazil, Canada, China, Egypt, France, Germany, India, Indonesia, Italy, Mexico, Nigeria, the Philippines, Romania, South Africa, Spain, Thailand, Ukraine, and the United States

An earlier study assessed green and blue WFs for all bioenergy types, including bioethanol (Gerbens-Leenes et al., 2009a). That study also calculated WFs for carbohydrate-rich crops that do not yet have a large-scale application for ethanol production. These crops were barley, cassava, potato, rice, rye, sorghum, and wheat. For the purpose of this chapter, we use data from Gerbens-Leenes et al. (2009a) and adopt the gray WFs of Gerbens-Leenes and Hoekstra (2012). For the United States, we present data from Gerbens-Leenes and Hoekstra (2012).

Mellko (2008) calculated the WFs of biofuels, including those of bioethanol and biodiesel, for the European Union and other large producing countries. Mellko applied the WF methodology and derived WF crop data from Chapagain and Hoekstra (2004) that were updated later (Gerbens-Leenes et al., 2009a, 2009b). Yang et al. (2009) have calculated the total WF of bioethanol from sugar beet grown in China. Chiu et al. (2009) estimated the amount of embodied water for ethanol in the United States and calculated the blue WF using the measured irrigation water. A fourth study included for comparison is the study of Berndes (2002), who has also given values for crop evapotranspiration per unit of bioenergy. The most recent study considered in this chapter is by Mekonnen and Hoekstra (2010); it provides a comprehensive global database of green, blue, and gray WFs of crops and derived crop products, including bioethanol and biodiesel, at a spatial resolution of $5 \times 5$ arcminute. 


\subsection{Biodiesel}

Gerbens-Leenes et al. (2009a) have calculated the WFs of biodiesel from rapeseed and soybean for the main producing countries:

- Rapeseed. India, Bangladesh, Pakistan, Australia, the United States, Canada, China, Poland, the Czech Republic, France, Denmark, the United Kingdom, and Germany

- Soybeans. India, Indonesia, China, Bolivia, the United States, Canada, Brazil, Argentina, Paraguay, and Italy

For jatropha, Gerbens-Leenes et al. (2009c) and Hoekstra et al. (2009) have calculated green and blue WFs for locations distributed over the Jatropha curcas belt (between $30^{\circ} \mathrm{N}$ and $35^{\circ} \mathrm{S}$ ), including Brazil, Indonesia, Nicaragua, Guatemala, and India. For palm oil, van Lienden et al. (2010) calculated the WF for the Philippines, Thailand, Indonesia, Malaysia, and Honduras. For the purposes of this chapter, we adopt the WF estimates of biodiesel from Gerbens-Leenes et al. (2009a, 2009c) and van Lienden et al. (2010).

\subsection{Heat and electricity generation from biomass}

Crop burning can provide heat for different societal uses. Gerbens-Leenes et al. (2009b) have calculated the WFs of heat generation from the combustion of biomass $\left(\mathrm{m}^{3} / \mathrm{GJ}\right)$ from different sources, including poplar (a tree); miscanthus (a nonfood crop); and cassava, coconut, cotton, groundnuts, maize, palm oil, potato, wheat, rapeseed, sugar beet, sugarcane, sunflower, and soybean (crops that can be used as food or feed). That study included four countries: the Netherlands, Brazil, the United States, and Zimbabwe. Gerbens-Leenes et al. (2009a) calculated the WF of heat generation from four biomass categories, including the following:

- Starch crops. Barley, maize, rice, rye, sorghum, wheat, cassava, potato

- Sugar crops. Sugar beet and sugarcane

- Oil crops. Rapeseed and soybean

- Trees. Jatropha

Significant amounts of heat are released during biomass combustion. This heat can be converted into electricity, with the amount of generated electricity depending on the efficiency of the power plant. Theoretically, there is a maximum amount of electricity that can be generated in a power plant (Blok, 2006). A new technology is the gasification of biomass for electricity production, termed biomass fired integrated gasifier/combined cycle (BIG/CC). It can be applied for biomass with a moisture content below 70 percent and an ash content below 10 to 20 percent (DM) (Faay, 1997). Temperatures are relatively low, however, at $720 \mathrm{~K}$, reaching an efficiency of 


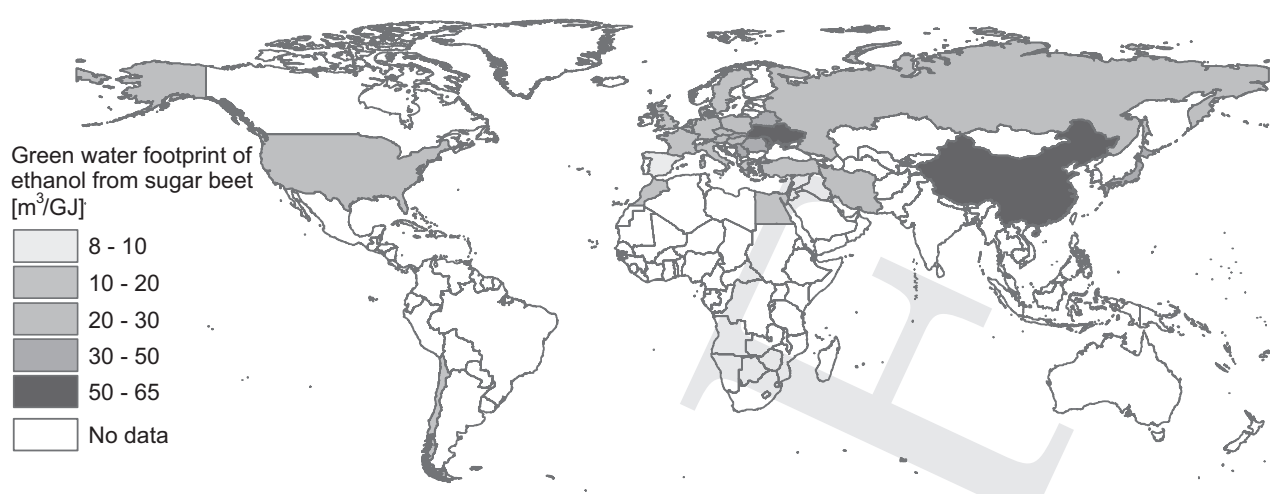

(a)

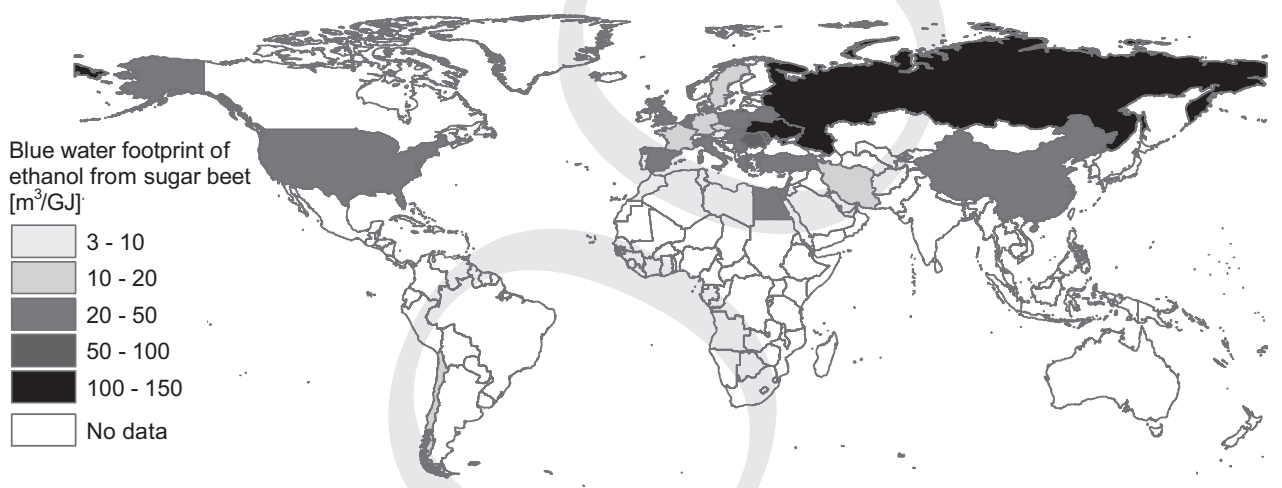

(b)

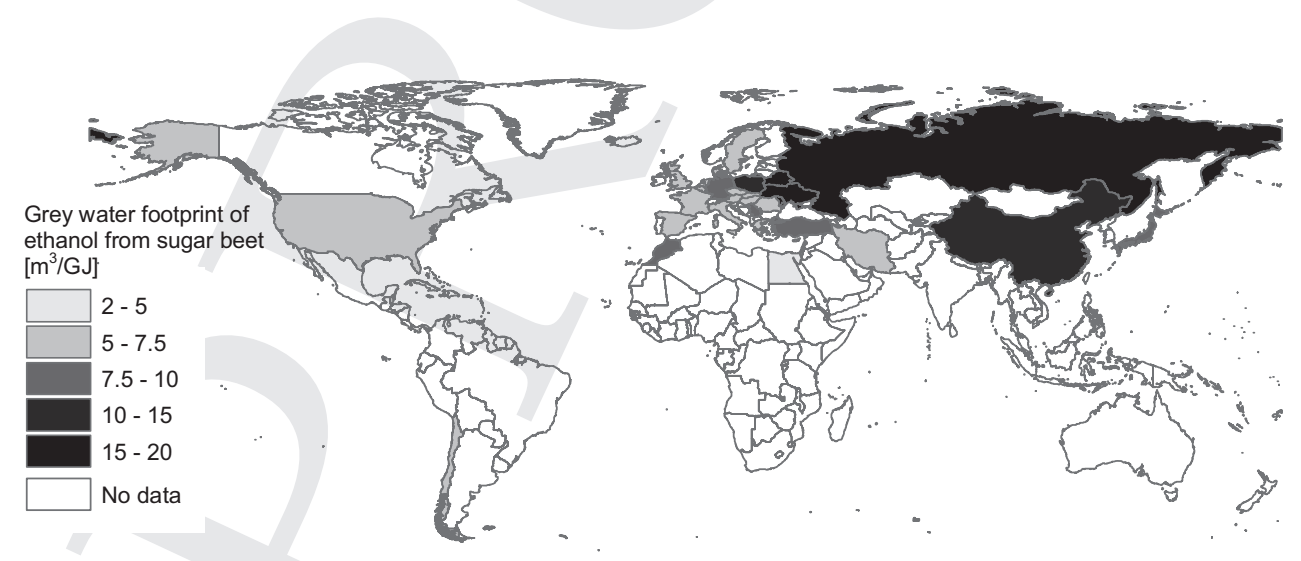

(c)

Figure 4.1. Weighted average (a) green, (b) blue, (c) gray, and (d) total WFs of ethanol from sugar beet $\left(\mathrm{m}^{3} / \mathrm{GJ}\right)$ for five regions. (See color plate.) 


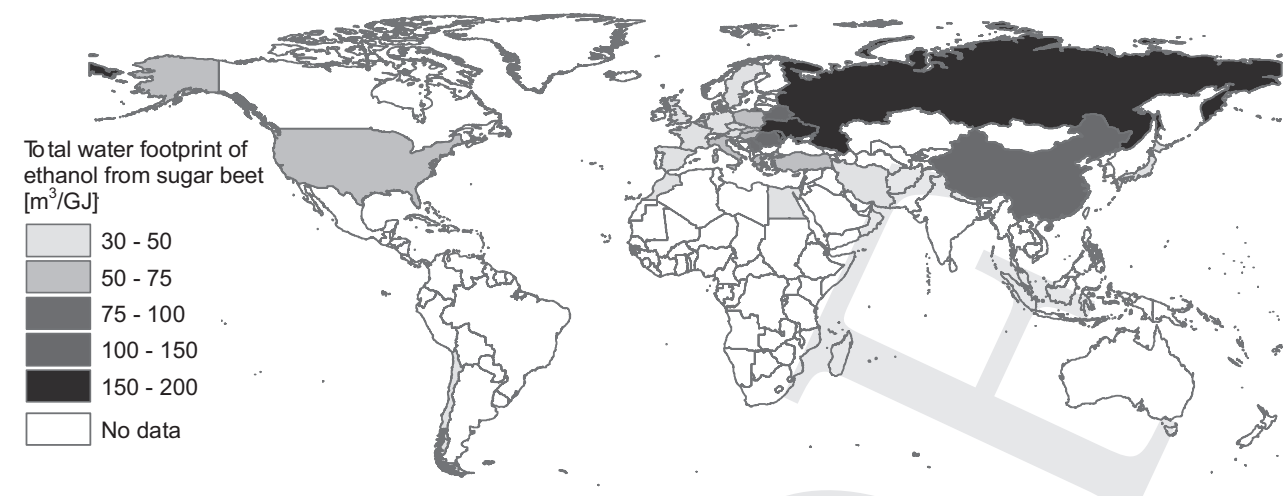

(d)

Figure 4.1 (continued)

59 percent (Blok, 2006). The WF results presented in this chapter are based on an electricity generation efficiency of 59 percent.

\subsection{Other energy carriers}

At present, important energy carriers include fossil energy carriers (crude oil, coal, and natural gas), uranium, and electricity from hydropower (IEA, 2006). Promising renewables are solar and wind energy. We compared the WFs of biofuels with the WFs of these important energy carriers. For crude oil, coal, natural gas, and uranium, we derived data from literature (Gleick, 1994). For electricity from hydropower, we estimated the global WF by dividing the global evaporation of reservoirs (Shiklomanov, 2000) by the hydroelectric generation (Gleick, 1993) for the year 1990. Next, we compared these results with information on WFs of hydropower from Mekonnen and Hoekstra (2011).

\section{Results}

\subsection{Bioethanol}

Figure 4.1 shows the weighted average green, blue, gray, and total WFs $\left(\mathrm{m}^{3} / \mathrm{GJ}\right)$ of bioethanol from sugar beet for five regions (northern Africa, the European Union, the United States, Asia, and eastern Europe). The global average is $70 \mathrm{~m}^{3} / \mathrm{GJ}$ (green WF, 36\%; blue WF, 51\%; and gray WF, 13\%). Morocco and Egypt have relatively small green WFs. Green WFs are large for Ukraine and China. Figure 4.1 shows that blue and gray WFs in particular are much greater in eastern Europe than in the other regions. The contribution of eastern Europe to global production, however, is only 11 percent so that these large WFs have a limited impact on the global WF. The largest contribution to global production is from the European Union. On the basis of 


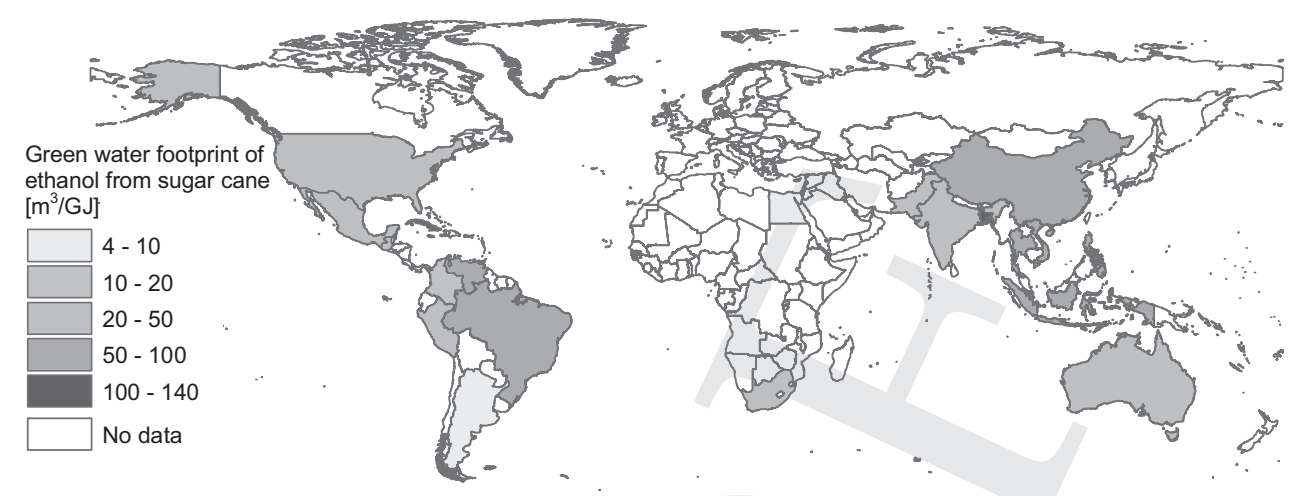

(a)

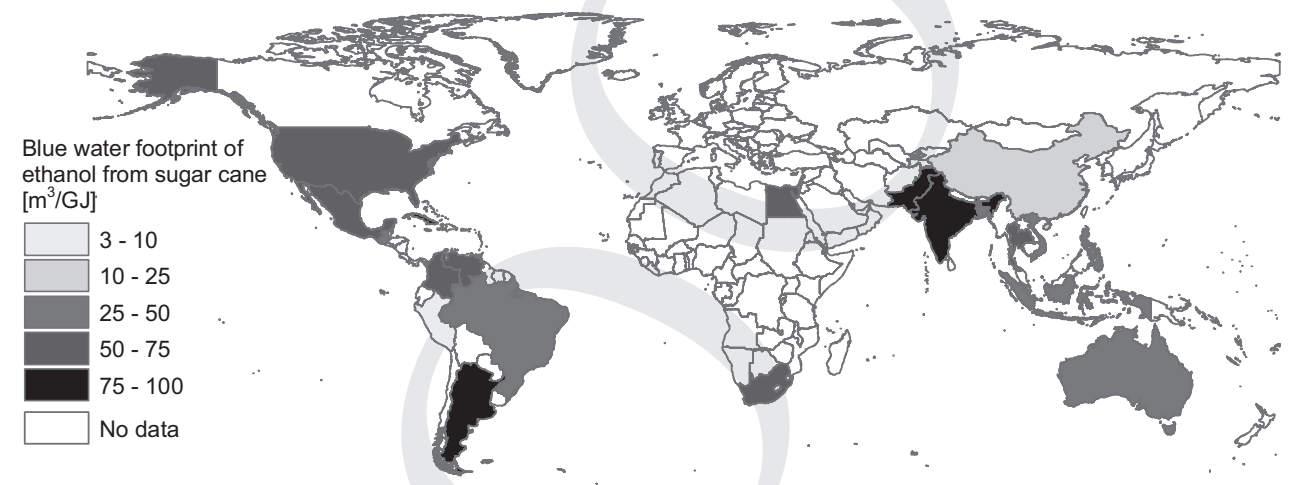

(b)

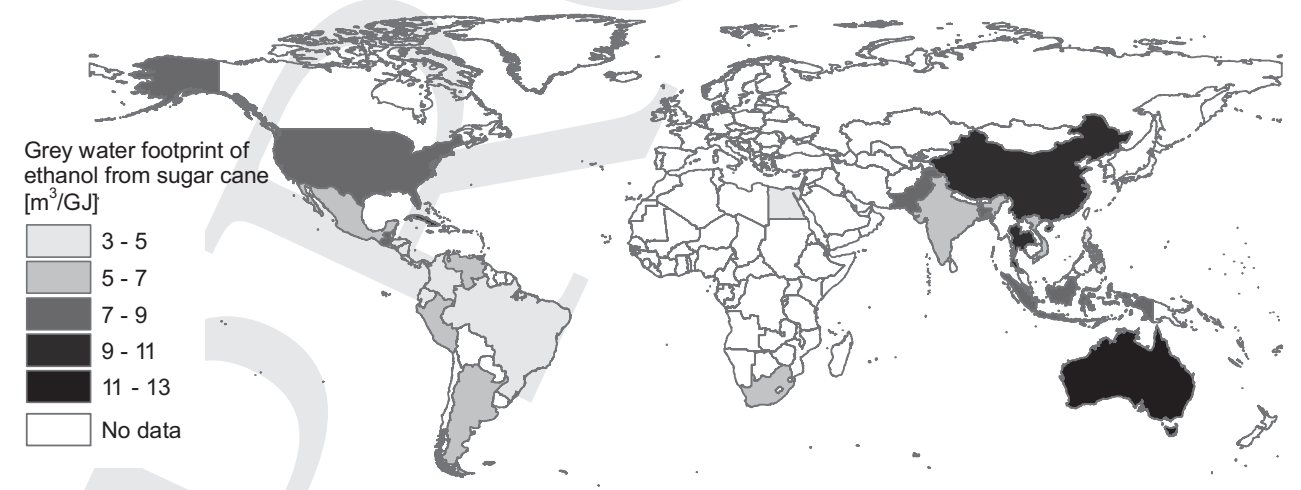

(c)

Figure 4.2. Weighted average (a) green, (b) blue, (c) gray, and (d) total WFs of ethanol from sugarcane for four regions. (See color plate.) 


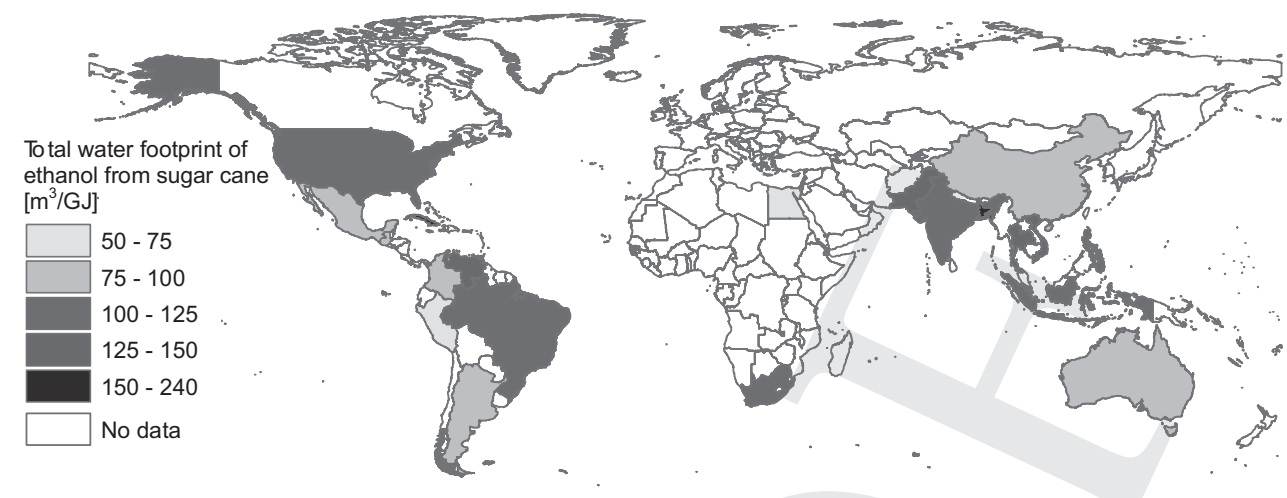

(d)

Figure 4.2 (continued)

FAO (2008a) production data, 54 percent of global sugar beet production is generated in the European Union.

Figure 4.2 shows weighted average green, blue, gray, and total WFs of bioethanol from sugarcane for four regions (northern Africa, represented by Egypt; Australia; the United States; and Asia). The global weighted average value is $115 \mathrm{~m}^{3} / \mathrm{GJ}$ (green WF, 43\%; blue WF, 50\%; and gray WF, 7\%). The WFs are below average in Egypt and Australia, about average in the United States, and above average in Asia. Argentina, Pakistan, and India have large blue WFs compared to the other countries because very small quantities of green water are available. The gray WF is large in Australia, at $13 \mathrm{~m}^{3} / \mathrm{GJ}$, whereas values for Egypt and the United States are only $3 \mathrm{~m}^{3} / \mathrm{GJ}$ and $5 \mathrm{~m}^{3} / \mathrm{GJ}$, respectively. The contribution of Australia to global production, however, is small, given that 43 percent of global production takes place in the Americas (mainly in Brazil) and an additional 45 percent in Asia. It is worth noting that the WFs of sugarcane ethanol of the major bioethanol producers in the developing world are relatively higher than global weighted averages. In particular, Brazil shows a WF of $210 \mathrm{~m}^{3} / \mathrm{GJ}$ (green WF, 55\%; blue WF, 41\%; and gray WF, 4\%), South Africa shows a WF of $306 \mathrm{~m}^{3} / \mathrm{GJ}$ (green WF, 33\%; blue WF, 61\%; and gray WF, 6\%), and India shows a WF of $256 \mathrm{~m}^{3} / \mathrm{GJ}$ (green WF, 33\%; blue WF, 61\%; and gray WF, 6\%).

Figure 4.3 shows the global weighted average green, blue, gray, and total WFs of bioethanol from maize for five regions (the European Union, the United States, Africa, Asia, and eastern Europe). The total global weighted average WF is $120 \mathrm{~m}^{3} / \mathrm{GJ}$ (green WF, 56\%; blue WF, 36\%; and gray WF, 9\%). The WFs are below average in the western European Union and the United States and above average in Mexico, Nigeria, Ukraine, Romania, India, Indonesia, and the Philippines. A comparison of Figures 4.1 and 4.3 shows the relatively large WFs for bioethanol from sugar beet and maize grown in eastern Europe. For sugar beet and maize, the green WF is twice as large as the green WF in the European Union. For sugar beet, the gray WF is two and a half times the European Union value. For maize, the gray WF is 13 percent larger than 


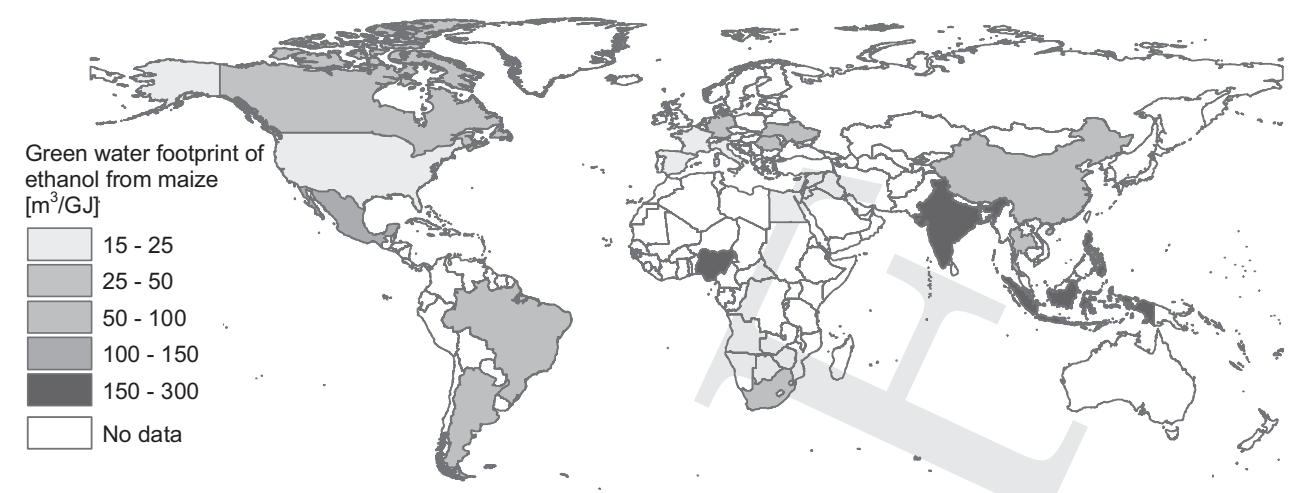

(a)

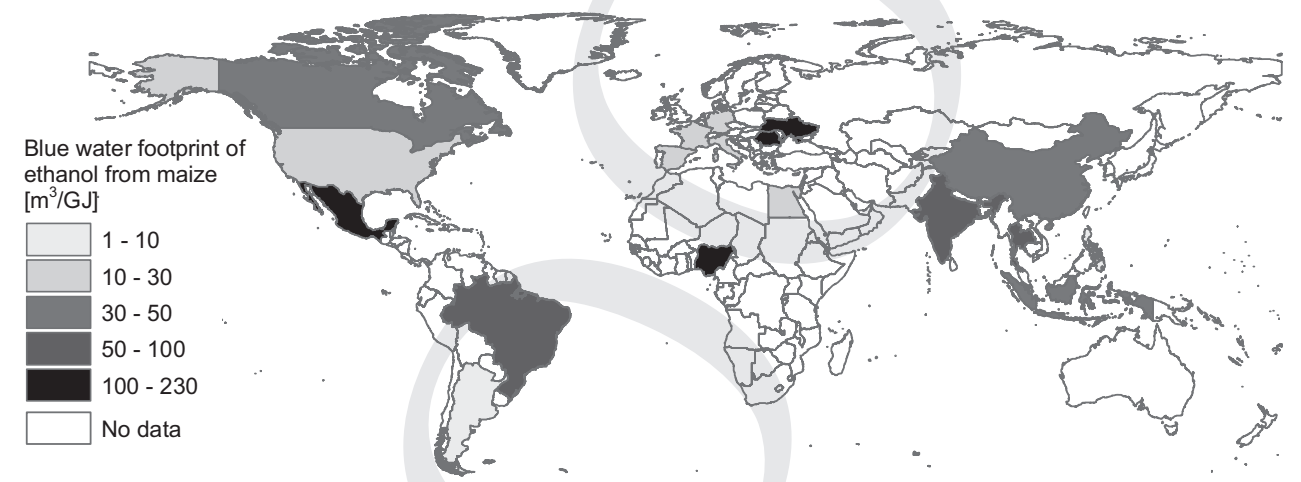

(b)

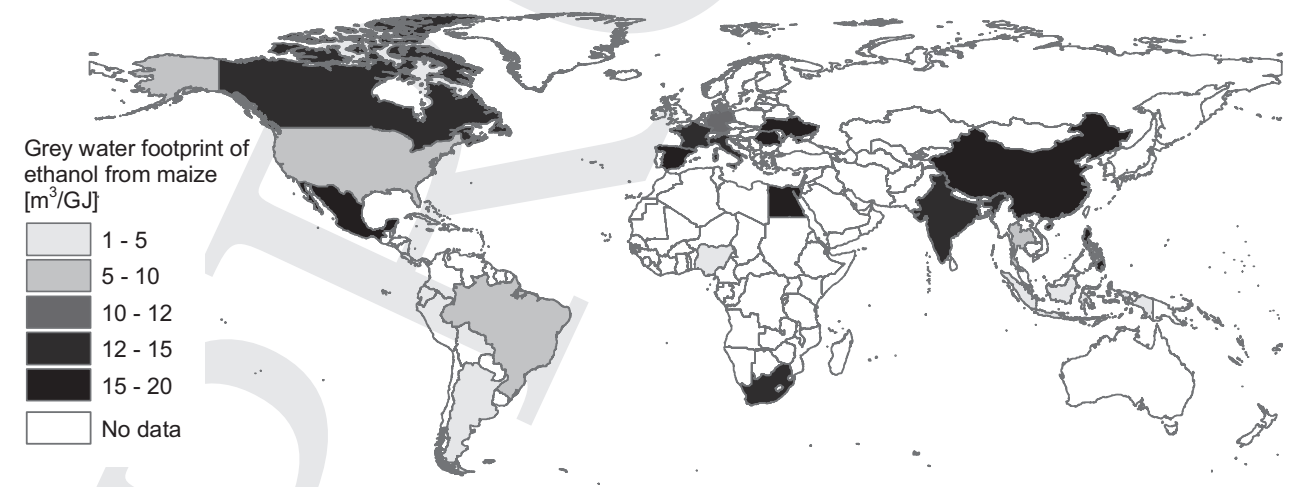

(c)

Figure 4.3. Global weighted average (a) green, (b) blue, (c) gray, and (d) total WFs of ethanol from maize for five regions. (See color plate.) 


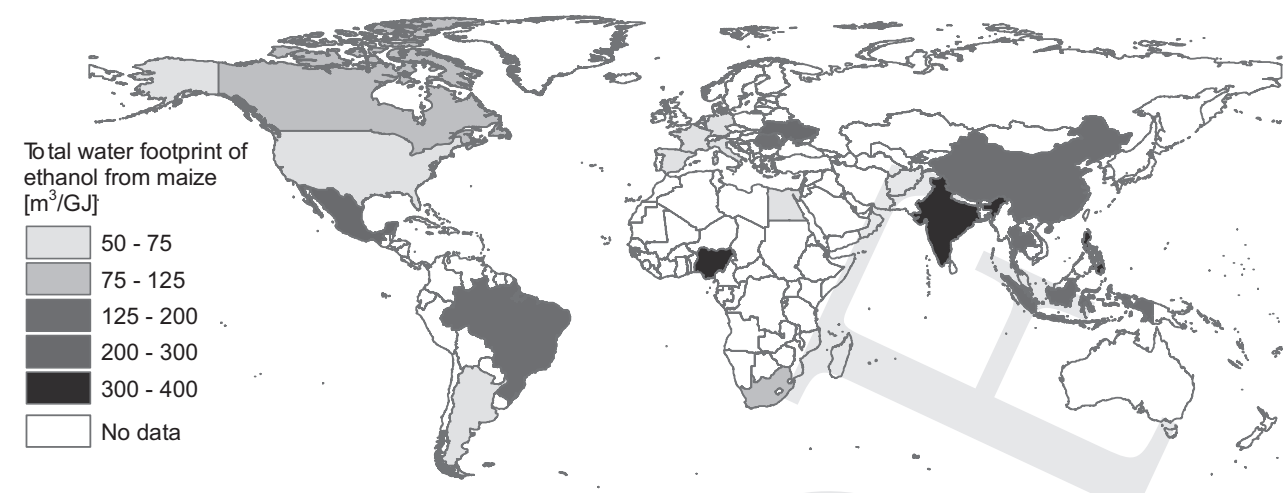

(d)

Figure 4.3 (continued)

in the European Union. The contribution to global production, however, is small and mainly comes from Asia (25\%) and the United States, which contributes 56 percent.

Figure 4.4 shows the green, blue, gray, and total WFs of bioethanol from maize in the United States for 10 states. The weighted U.S. average WF is $54 \mathrm{~m}^{3} / \mathrm{GJ}$ (green WF, 44\%; blue WF, 37\%; and gray WF, 19\%). The results show some variation but are smaller than the global weighted average, with a green WF of 67, a blue WF of 43, and a gray WF of $11 \mathrm{~m}^{3} / \mathrm{GJ}$.

Figure 4.5 shows the global average green and blue WFs of bioethanol from maize, sugar beet, sugarcane, potato, cassava, barley, rye, paddy rice, wheat, and sorghum. The WF of potato bioethanol is $100 \mathrm{~m}^{3} / \mathrm{GJ}$, while the WF of sorghum bioethanol is more than four times the WF of potato bioethanol. The remaining crops have WFs between these two extremes. Figure 4.5 also shows the large variation among green and blue WFs.

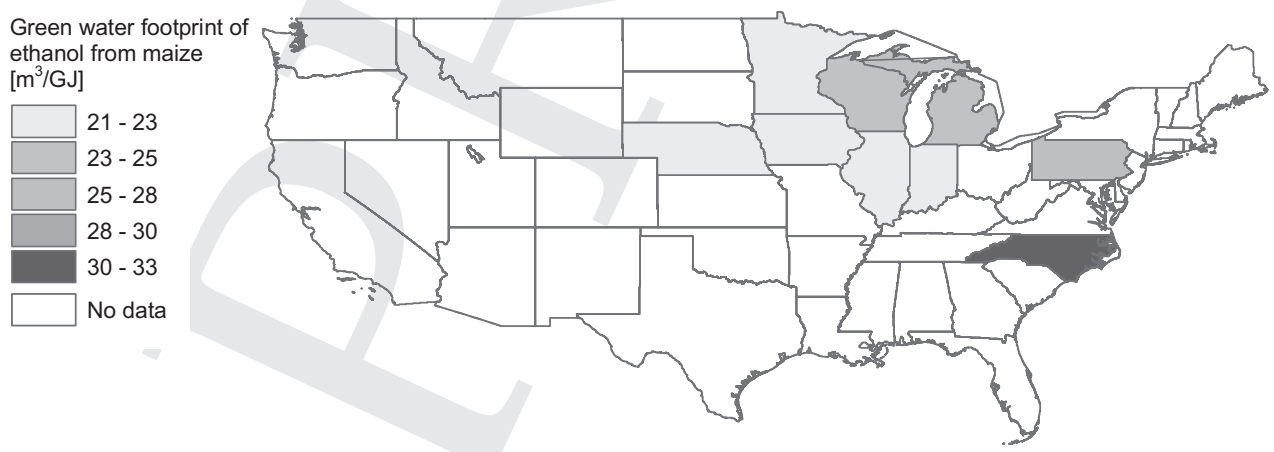

(a)

Figure 4.4. (a) Green, (b) blue, (c) gray, and (d) total WFs of ethanol from maize in the United States for 10 states. (See color plate.) 

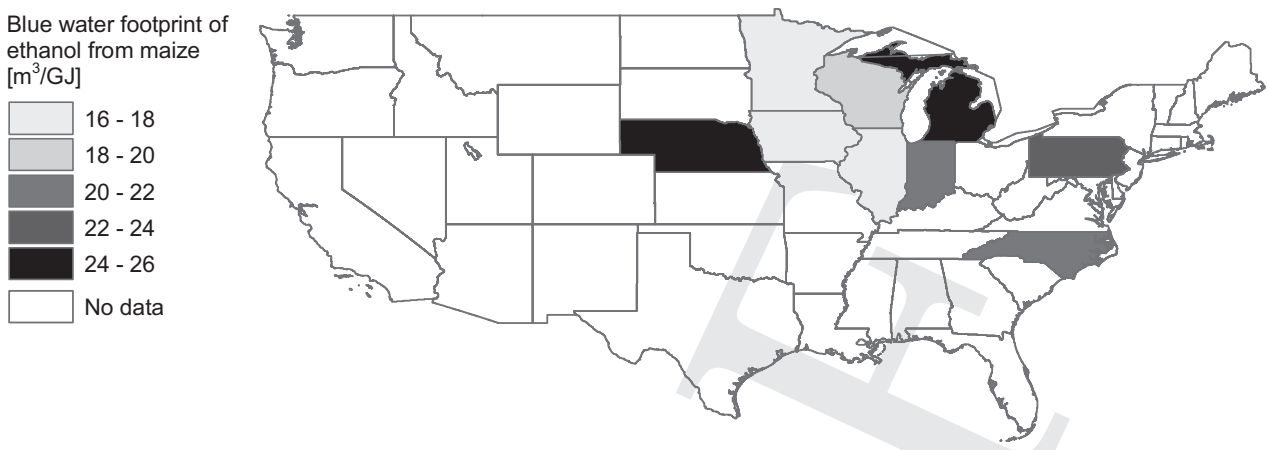

(b)
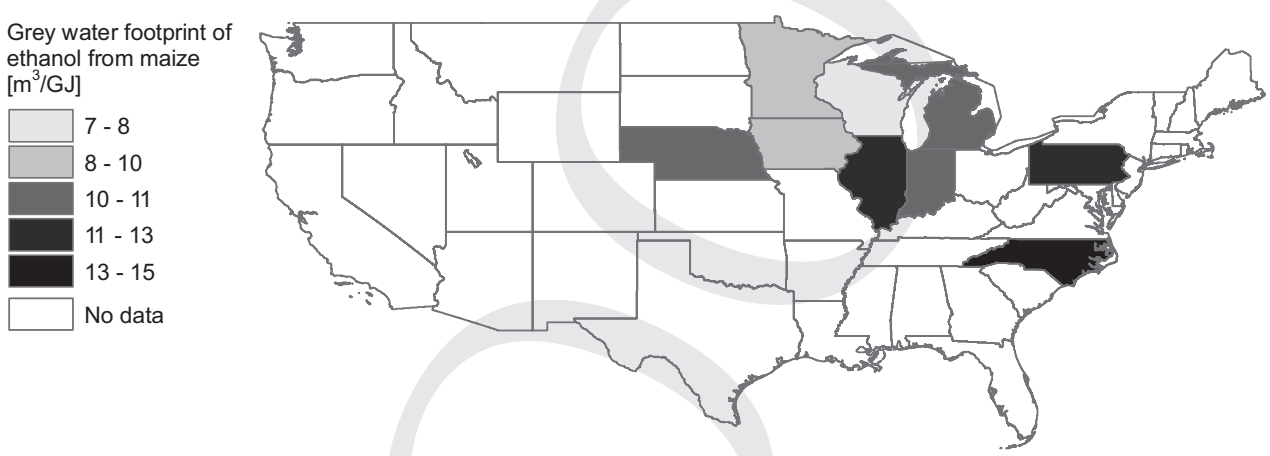

(c)
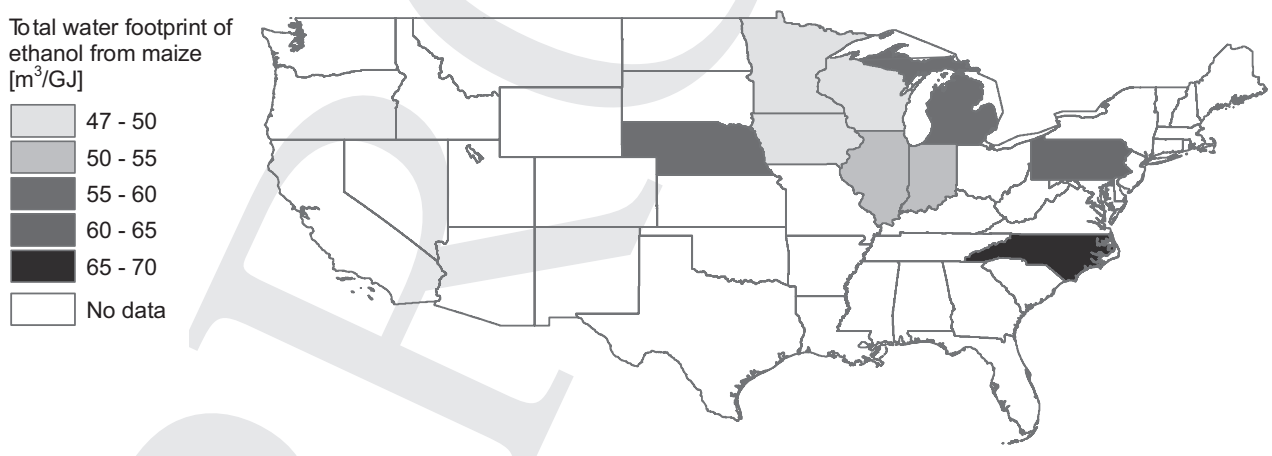

(d)

Figure 4.4 (continued)

\subsection{Biodiesel}

Table 4.1 gives the green, blue, and total WFs of jatropha, palm oil, rapeseed, soybean oil, and sunflower oil biodiesel in different areas of the world. The WFs of biodiesel from jatropha oil are greatest, followed by WFs of soybean and rapeseed oil. The WFs of biodiesel from palm oil and sunflower oil are the lowest. Table 4.1 also 


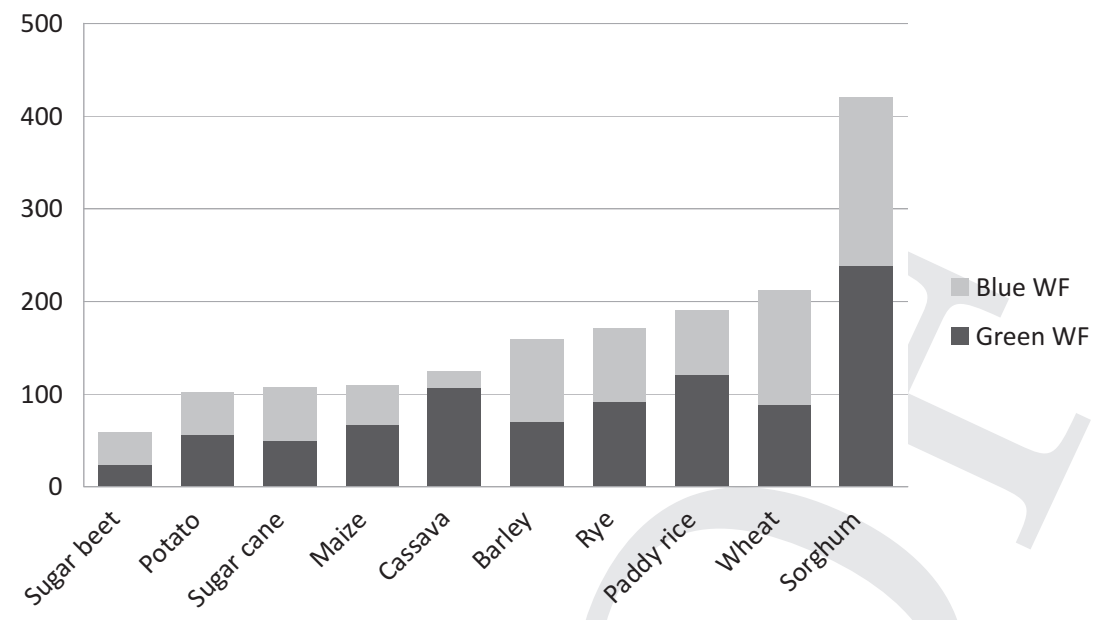

Figure 4.5. Global average green and blue WFs of ethanol from sugar beet, potato, sugarcane, maize, cassava, barley, rye, paddy rice, wheat, and sorghum.

Table 4.1. Green, blue, and total wfs of jatropha, palm oil, rapeseed, soybean oil, and sunflower oil biodiesel for different locations

\begin{tabular}{|c|c|c|c|c|}
\hline & & Green WF & Blue WF & Total WF \\
\hline \multirow[t]{6}{*}{ Jatropha oil $^{a}$} & India & 575 & 1,116 & 1,691 \\
\hline & Guatemala & 156 & 174 & 329 \\
\hline & Nicaragua & 120 & 187 & 307 \\
\hline & Indonesia & 184 & 109 & 293 \\
\hline & Brazil & 160 & 91 & 251 \\
\hline & Average & 239 & 335 & 574 \\
\hline \multirow[t]{4}{*}{ Rapeseed oil ${ }^{a}$} & India & 256 & 591 & 847 \\
\hline & China & 185 & 238 & 422 \\
\hline & Germany & 78 & 49 & 127 \\
\hline & Global weighted average & 165 & 245 & 409 \\
\hline \multirow[t]{4}{*}{ Soybean oil ${ }^{a}$} & United States & 227 & 216 & 443 \\
\hline & Argentina & 128 & 115 & 244 \\
\hline & Italy & 108 & 117 & 225 \\
\hline & Global weighted average & 177 & 217 & 394 \\
\hline \multirow[t]{6}{*}{ Palm oil ${ }^{b}$} & Philippines & 70 & 54 & 124 \\
\hline & Thailand & 53 & 44 & 97 \\
\hline & Indonesia & 64 & 26 & 90 \\
\hline & Malaysia & 67 & 1 & 68 \\
\hline & Honduras & 87 & 9 & 96 \\
\hline & Average & 68 & 27 & 95 \\
\hline Sunflower oil ${ }^{c}$ & Average European Union & & & 93 \\
\hline
\end{tabular}

Note: Units are $\mathrm{m}^{3} / \mathrm{GJ}$ oil.

a Source: Gerbens-Leenes et al. (2009a).

$b$ Source: van Lienden et al. (2010).

c Source: Mellko (2008). 
Table 4.2. Global weighted average water footprint of heat from total biomass for 12 crops

\begin{tabular}{lccc}
\hline \hline & \multicolumn{3}{c}{ Global weighted average WF $\left(\mathrm{m}^{3} / \mathrm{GJ}\right)$} \\
\cline { 2 - 4 } Crop & Total WF & Green WF & Blue WF \\
\hline Sugar beet & 27 & 11 & 16 \\
Maize & 30 & 18 & 12 \\
Sugarcane & 32 & 15 & 17 \\
Barley & 42 & 20 & 22 \\
Paddy rice & 48 & 28 & 21 \\
Wheat & 56 & 23 & 32 \\
Potatoes & 60 & 33 & 27 \\
Cassava & 87 & 75 & 13 \\
Soybeans & 102 & 46 & 56 \\
Sorghum & 107 & 61 & 47 \\
Rapeseed & 226 & 91 & 135 \\
Jatropha & 234 & 97 & 136 \\
\hline \hline
\end{tabular}

shows significant differences among locations and averages for countries. In India, for example, the WF of biodiesel from jatropha oil is twice the WF of biodiesel from rapeseed oil. In Indonesia, the WF of biodiesel from jatropha oil is three times the WF of biodiesel from palm oil.

\subsection{Heat and electricity generation from biomass}

Table 4.2 includes the global weighted average green, blue, and total WFs of heat generation from biomass combustion for 12 crops. There is a large variation among the different crops. The total WF of heat generation from total sugar beet biomass is almost 10 times smaller than values for rapeseed and jatropha (whole fruit yield).

Table 4.3 provides the WFs of heat generation from total biomass combustion for a tree (poplar) and five crops (miscanthus, sunflower, sugar beet, sugarcane, and maize) for three countries. Table 4.3 shows that poplar and miscanthus (which are also feedstocks for second-generation biofuels) do not have a more favorable WF than food crops. In the Netherlands, the WF of heat generated from maize combustion is half the WF of heat generated from poplar or miscanthus combustion. In the United States, maize is the most favorable crop in terms of WF, whereas in Brazil, the most favorable crop is sugarcane.

When WFs for bioethanol are compared to WFs for heat, results show that it is much more favorable to generate heat than to produce biofuels. Depending on crop type, WFs for heat generation are much lower than bioethanol WFs. For example, the WFs of bioethanol from cassava are 50 percent higher than the WFs of heat generated 
Table 4.3. Water footprint of heat for one tree type, poplar, and five crop types, miscanthus, sunflower, sugar beet, sugarcane, and maize, grown in three countries

\begin{tabular}{lccc}
\hline \hline & \multicolumn{3}{c}{$\begin{array}{c}\text { WF of heat generation from total } \\
\text { biomass combustion }\left(\mathrm{m}^{3} / \mathrm{GJ}\right)\end{array}$} \\
\cline { 2 - 4 } Trees and crops & The Netherlands & United States & Brazil \\
\hline Maize & 9 & 21 & 38 \\
Sugar beet & 16 & 25 & - \\
Sugarcane & - & 31 & 29 \\
Miscanthus & 20 & 37 & 49 \\
Poplar & 22 & 42 & 55 \\
Sunflower & 27 & 61 & 54 \\
\hline \hline
\end{tabular}

from cassava, while the WFs of ethanol from barley are four times the WF of heat from barley. Also for soybean, rapeseed, and jatropha, biodiesel WFs are two to four times greater than the WFs for heat generation.

The WF of bioelectricity was estimated from the WF of total crop biomass, including stems and leaves, assuming an efficiency of 59 percent for the conversion of heat into bioelectricity. The WF of electricity can be derived from the data given in Table 4.2 and the conversion efficiency of 59 percent.

\subsection{Comparison with other studies}

Table 4.4 provides a comparison of the findings from Mellko (2008) with the results presented in this chapter. Although the studies do not always cover the same countries, the results for total WFs are similar. Additionally, Mellko gives a value for sunflower oil. The data presented in this chapter show the same pattern as in the recent study by Mekonnen and Hoekstra (2010) but tend to be a bit higher, which can be explained by the fact that the latter study included the effect of water shortages in agriculture, an effect not included in the data presented here.

Yang et al. (2009) have calculated the total WF of ethanol from sugar beet grown in China to be $96 \mathrm{~m}^{3} / \mathrm{GJ}$, while we arrived at $97 \mathrm{~m}^{3} / \mathrm{GJ}$. In the U.S. context, Chiu et al. (2009) measured actual irrigation and arrived at values between $0.3 \mathrm{~m}^{3} / \mathrm{GJ}$ (Iowa and Kentucky) and $91.4 \mathrm{~m}^{3} / \mathrm{GJ}$ (California), with a weighted average of $6 \mathrm{~m}^{3} / \mathrm{GJ}$. This value is small compared to the value of $20 \mathrm{~m}^{3} / \mathrm{GJ}$ for the U.S. bioethanol blue WF calculated by Gerbens-Leenes et al. (2009a). The main reason behind this discrepancy is that the study by Chiu et al. (2009) considered more states and included states, such as California, that have a dry season. Conversely, the study by Gerbens-Leenes et al. (2009a) estimated the WF of only the 10 main producing states. 
Table 4.4. Comparison of WFs estimated in different studies

\begin{tabular}{|c|c|c|c|c|}
\hline & Mellko (2008) & $\mathrm{m}^{3} / \mathrm{GJ}$ & $\begin{array}{l}\text { Gerbens-Leenes et al. (2009a, } \\
2009 b)^{1} \text { and van Lienden et al. } \\
(2010)^{2}\end{array}$ & $\mathrm{~m}^{3} / \mathrm{GJ}$ \\
\hline \multicolumn{5}{|l|}{ Ethanol } \\
\hline Barley & EU 27 & 126 & 14 largest European producers ${ }^{1}$ & 178 \\
\hline Sugar beet & EU 27 & 51 & 18 largest European producers ${ }^{1}$ & 49 \\
\hline Wheat & EU 27 & 108 & 9 largest European producers ${ }^{1}$ & 196 \\
\hline \multirow[t]{2}{*}{ Maize } & $\begin{array}{l}\text { China, India, } \\
\text { United States }\end{array}$ & 101 & China, India, United States ${ }^{1}$ & 170 \\
\hline & United States & 51 & United States $^{1}$ & 44 \\
\hline \multirow[t]{4}{*}{ Sugarcane } & India & 78 & India $^{1}$ & 118 \\
\hline & South Africa & 96 & South Africa $^{1}$ & 98 \\
\hline & Brazil & 76 & Brazil $^{1}$ & 99 \\
\hline & $\begin{array}{l}\text { Average India, } \\
\text { South Africa, } \\
\text { Brazil }\end{array}$ & 83 & Global weighted average $^{1}$ & 108 \\
\hline \multicolumn{5}{|l|}{ Biodiesel } \\
\hline Sunflower & $\begin{array}{l}13 \text { EU } \\
\text { countries }\end{array}$ & 93 & NA & - \\
\hline Rapeseed & EU 27 & 133 & 6 European countries ${ }^{1}$ & 139 \\
\hline Palm oil & $\begin{array}{l}\text { Indonesia, } \\
\text { Malaysia }\end{array}$ & 86 & $\begin{array}{l}\text { Philippines, Thailand, Indonesia, } \\
\text { Malaysia, Honduras }\end{array}$ & 95 \\
\hline
\end{tabular}

Berndes (2002) has also given values for crop evapotranspiration per unit of bioenergy and has arrived at a large variation in values. Table 4.5 compares the results of Berndes (2002) with the results of Gerbens-Leenes et al. (2009a).

\subsection{Comparison with the WF of other primary energy carriers}

Table 4.6 gives an overview of the energy carriers' WFs derived from the literature (Gleick, 1994). Although the data are rather old, they give an indication of the WFs

Table 4.5. Comparison of crop evapotranspiration per unit of bioenergy from different studies

\begin{tabular}{lll}
\hline \hline Crop & Berndes (2002) & Gerbens-Leenes et al. (2009a) \\
\hline Sugar beet & $71-188$ & $22-174$ \\
Maize & $73-346$ & $41-377$ \\
Sugarcane & $37-155$ & $47-225$ \\
Wheat & $40-351$ & $50-1,001$ \\
Rapeseed & $100-175$ & $127-847$ \\
\hline \hline
\end{tabular}

Note: Units are in $\mathrm{m} 3 / \mathrm{GJ}$. 
Table 4.6. Water footprint of different energy carriers

\begin{tabular}{ll}
\hline \hline Energy carrier & Average WF $\left(\mathrm{m}^{3} / \mathrm{GJ}\right)$ \\
\hline Wind energy $^{a}$ & 0.0 \\
Nuclear energy $^{a}$ & 0.1 \\
Natural gas $^{a}$ & 0.1 \\
Coal $^{a}$ & 0.2 \\
Solar thermal energy $^{a}$ & 0.3 \\
Crude oil $^{a}$ & 1.1 \\
Hydropower $^{b, c}$ & $0.5-850$ \\
Bioethanol $^{d}$ & 165 \\
Biodiesel $^{d}$ & 313 \\
\hline \hline
\end{tabular}

Note: Units are in $\mathrm{m}^{3} / \mathrm{GJ}$.

a Source: Gleick (1994).

${ }^{b}$ Sources: Gleick (1993) and Shiklomanov (2000).

c Source: Mekonnen and Hoekstra (2011).

${ }^{d}$ Global weighted average.

of conventional energy carriers. WFs of crude oil, coal, natural gas, uranium, solar thermal energy, and wind electricity generation are all smaller than the WFs of biomass. For fossil fuels, it should be noted, however, that the water required over time to grow the vegetation that has accumulated and turned into fossil fuel is excluded from the figures presented. For a fair comparison between the water footprint of bioenergy and fossil fuels, this historically accumulated water consumption should be accounted for.

For hydropower, Gerbens-Leenes et al. (2009b) have found an average global WF of $22 \mathrm{~m}^{3} / \mathrm{GJ}$, while Mekonnen and Hoekstra (2011) have arrived at an average value of $68 \mathrm{~m}^{3} / \mathrm{GJ}$. WF values per unit of generated electricity, however, show enormous variation. For example, the Lubuge power plant in China uses only $0.5 \mathrm{~m}^{3} / \mathrm{GJ}$ of generated electricity. Conversely, the Akosombo dam and Kpong power plant in Ghana use $850 \mathrm{~m}^{3} / \mathrm{GJ}$ of generated electricity, which is the highest WF for any energy source discussed in this chapter so far. WFs of hydropower and bioenergy are much higher than WFs of other energy sources. The global weighted average WF for bioethanol is $165 \mathrm{~m}^{3} / \mathrm{GJ}$, and for biodiesel, it is $313 \mathrm{~m}^{3} / \mathrm{GJ}$. When these data are also compared to the results presented elsewhere in the chapter, the large WF of bioenergy, especially for the first generation biofuels, becomes clear.

\section{Discussion}

In assessing the WFs of heat, electricity, and biofuels, all studies took into account the WF of the gross energy output from crops. Energy inputs in the production chain, such as energy requirements in the agricultural system (e.g., energy use for the production of fertilizers and pesticides) or the energy use during the industrial biofuel production 
process, were excluded. For high-input agricultural systems, energy input is substantial (Giampietro and Ulgiati, 2005; Pimentel and Patzek, 2005) so that net energy yields are smaller than presented here. This means that this overview underestimates the WF of bioenergy from agricultural systems with relatively large energy inputs.

The WFs presented in this chapter are based on rough estimates of freshwater requirements in crop production, in combination with theoretical maximum conversion efficiencies in heat, bioelectricity, and biofuel production. The studies have integrated data from several sources, each adding a degree of uncertainty. Meteorological data, for example, are averages over several years rather than representing data for a specific year and do not reflect annual variations. Calculations of crop water requirements are sensitive to input of climatic data and assumptions concerning the start of the growing season. The data on energy carriers from the literature (Gleick, 1994) give an indication of water requirements but are probably outdated. Therefore results are indicative. However, the differences among the WFs of different energy carriers are so great that they support general conclusions with respect to relative WFs of different types of bioenergy, crops, and countries.

It is worth mentioning that the WF of second-generation biofuels will be higher than the WFs of heat generation because the biomass needs to be converted into biofuel, which will probably have a conversion efficiency of less than 100 percent. How much of the WF of a crop that delivers both food and second-generation energy will be allocated to the energy component depends on the value of the energy derived from $1 \mathrm{~kg}$ of harvested crop relative to the value of food coming from the same kilogram of crop.

Our results show that the WFs of bioenergy and hydropower are large. A policyrelevant question is whether (and to what extent) water should be used for food, fibers, or fuel. This is especially relevant in developing countries with increasing populations, such as China and India, where the demand for food will increase. Large biofuel and hydropower programs may need large amounts of water, making the water unavailable for food production. Another issue is the sustainability of energy with large water requirements. Whether the WF related to the production of bioenergy and hydropower is sustainable depends on two criteria: the geographic context and the characteristics of the production process itself (Hoekstra et al., 2011). A WF is unsustainable when the process is located in a so-called hotspot, a catchment where during a certain period of the year environmental water needs are violated or pollution exceeds waste assimilation capacity. For example, when ethanol from sugarcane is produced in northern India, an area where water stress occurs, this is unsustainable. A WF is also considered unsustainable when the WF of the process can be reduced or avoided altogether. One could argue that allocating water to bioenergy or hydropower with large WFs is unsustainable because other renewables (e.g., sun and wind) have much smaller WFs. If the choice is made to produce bioenergy, however, the agricultural practices chosen should produce the feedstock in the most 
water-efficient way. The reduction of green WFs can be achieved by increasing land productivity. Blue WFs can be reduced with more efficient irrigation or by selecting alternative crops. Gray WFs can be reduced by applying fewer chemicals (e.g., thanks to the use of precision agriculture). We have shown the large differences in gray WFs among countries. An example of this is provided by eastern European countries, which have relatively large gray WFs, indicating an inefficient use of chemicals. Large improvements are possible under such scenarios.

\section{Conclusions}

The most water-efficient way to generate bioenergy is to use total biomass, including parts without a large economic value, and generate heat. The generation of electricity is the second best option. The production of first-generation biofuels requires about twice as much water per unit of energy as bioelectricity. When comparing different biofuel practices, it is more water efficient to produce ethanol than it is to produce biodiesel. The WF of a typical biodiesel energy crop, rapeseed, is four times larger than the WF of ethanol from sugarcane and seven times larger than the WF of ethanol from sugar beet.

WFs for similar energy carriers can show large variation, depending on the crop type applied, production location, and agricultural practice. The global weighted WF for ethanol increases in the following order: sugar beet, potato, sugarcane, maize, cassava, barley, rye, paddy rice, wheat, and sorghum; it ranges between 60 and 400 $\mathrm{m}^{3} / \mathrm{GJ}$. For sugar beet, maize, and sugarcane, the differences among regions are large. The European Union, northern Africa, and the United States have relatively small WFs for ethanol, whereas eastern Europe has large WFs for ethanol from sugar beet and maize. The global weighted average WF of biodiesel increases in the following order: palm oil $\left(95 \mathrm{~m}^{3} / \mathrm{GJ}\right)$, soybean and rapeseed $\left(400 \mathrm{~m}^{3} / \mathrm{GJ}\right)$, and jatropha $\left(570 \mathrm{~m}^{3} / \mathrm{GJ}\right)$.

When the WFs of bioenergy are compared to the WFs of hydropower or conventional fossil fuels, there are large differences. Hydropower in particular shows a wide range of values for WFs per unit of electricity generated, ranging from 0.5 to 850 $\mathrm{m}^{3} /$ GJ. The WF of heat generated from sugar beet is 25 times larger than the WF of crude oil, while the WF of jatropha biodiesel is 6,000 times larger than the WF of natural gas. A shift toward bioenergy brings a need for more water. A shift toward hydropower can also bring a need for more water, but this depends on the climate and the way in which the power is generated. The results presented in this chapter have led to new insight with respect to the large impact of bioenergy on the use of freshwater resources. This knowledge can make a valuable contribution to research concerning energy needs and freshwater availability in the near future. 